\title{
RF sputtering: A viable tool for MEMS fabrication
}

\author{
SUDHIR CHANDRA*, VIVEKANAND BHATT and \\ RAVINDRA SINGH
}

Centre for Applied Research in Electronics, Indian Institute of Technology Delhi, Hauz-Khas, New Delhi 110016

e-mail: schandra@care.iitd.ernet.in

\begin{abstract}
Fabrication of Micro-Electro-Mechanical-Systems (MEMS) requires deposition of films such as $\mathrm{SiO}_{2}, \mathrm{Si}_{3} \mathrm{~N}_{4}, \mathrm{ZnO}$, polysilicon, phosphosilicate glass (PSG), Al, Cr-Au, Pt, etc. for use as structural, sacrificial, piezoelectric and conducting material. Deposition of these materials at low temperature is desirable for fabricating sensors/actuators on temperature-sensitive substrates and also for integrating MEMS structures on silicon in post-CMOS processing procedures. Plasma enhanced chemical vapour deposition (PECVD) and sputtering are amongst potential techniques for preparing films for MEMS fabrication at comparatively low temperatures. The sputtering technique has an added advantage that the process is carried out in an inert ambient (argon) and chemically sensitive substrate/sacrificial layers can be used in realization of MEMS. Furthermore, the same system can be used for depositing dielectric, piezoelectric and conducting materials as per requirement in the fabrication sequence. This enables rapid low-cost prototyping of MEMS with minimum fabrication facilities.

In the present work, we report preparation, characterization and application of $\mathrm{RF}$ sputtered $\mathrm{SiO}_{2}, \mathrm{Si}_{3} \mathrm{~N}_{4}$ and $\mathrm{ZnO}$ films for MEMS fabrication. The effect of RF power, sputtering pressure and target-to-substrate spacing was investigated on the structural and other properties of the films. The residual stress in the films was obtained using wafer curvature measurement technique. The deposition parameters are optimized to obtain low stress films of $\mathrm{SiO}_{2}$ and $\mathrm{Si}_{3} \mathrm{~N}_{4}$. The self-heating of the substrate during deposition was advantageously exploited to obtain highly $c$-axis oriented films of $\mathrm{ZnO}$ without any external heating. A variety of MEMS structures such as cantilever beams, micro-bridges, diaphragms, etc. are demonstrated using bulk, surface and surface-bulk micromachining techniques.
\end{abstract}

Keywords. RF sputtering; dielectric films; piezoelectric films; MEMS; micromachining.

\section{Introduction}

Fabrication of Microelectromechanical Systems (MEMS) often requires deposition of thin film of dielectric, piezoelectric, semiconductor and metal such as silicon dioxide, silicon nitride, phosphosilicate glass (PSG), zinc oxide, polycrystalline/amorphous silicon,

*For correspondence 
chromium, gold, platinum, titanium etc. These materials are used as structural and sacrificial layers, sensing elements and for interconnection in sensors/actuators. In the fabrication sequence, the sensors/actuators are often realized in post-CMOS processing steps and the deposition conditions must then be compatible with the circuits already realized on the silicon wafer. This puts a limit (usually below $400^{\circ} \mathrm{C}$ ) on the processing temperature that can be used in sensor/actuator fabrication related steps. Furthermore, the sensors are sometimes fabricated on temperature-sensitive substrates (e.g. polymers) or use such materials as sacrificial layer (e.g. photoresist). This puts some additional restriction on the techniques, which can be used for deposition processes.

Silicon dioxide, silicon nitride, polycrystalline/amorphous silicon and PSG films are routinely used in IC fabrication process. Various types of chemical vapour deposition techniques are used for this purpose. Considering the requirement of deposition at low temperature (less than $400^{\circ} \mathrm{C}$ ), plasma enhanced chemical vapour deposition (PECVD) and RF sputtering are potentially suitable techniques. PECVD is the most widely accepted process for the deposition of $\mathrm{SiO}_{2}$, SiN, PSG and amorphous silicon films due to high throughput and excellent control of film properties. The RF sputtering process has some advantage in terms of: simple low-cost deposition system, absence of toxic/pyrophoric gases from the process and the possibility of sequential deposition of different films in the same system. These advantages have led to several recent research publications focusing on RF sputtering technique as a viable method of preparing dielectric/semiconductor films for MEMS applications (Folta et al 1994; Hurley \& Gamble 2003) While RF sputtered piezoelectric films of ZnO are extensively investigated over the past 20 years (Chu et al 2003; Ondo-Ndong et al 2003; Mitsuyu et al 1980), the ferroelectric films of lead zirconate titanate (PZT) and its derivatives are also now being prepared by RF sputtering and their application in MEMS being explored. $\mathrm{ZnO}$ films have recently been investigated as a sacrificial layer also in surface micromachining process (Bhatt et al 2005). It is visualized that RF sputtering can be advantageously used for rapid prototyping of several MEMS devices.

In the present work, we report preparation of silicon dioxide, silicon nitride and piezoelectric $\mathrm{ZnO}$ films by RF sputtering process. The properties of these films relevant for MEMS applications have been evaluated. The application of these films in fabricating basic MEMS structures such as diaphragm, micro-cantilever beams, etc. has been demonstrated.

\section{Experimental work}

\subsection{Film preparation}

Thin films of silicon dioxide, silicon nitride and zinc oxide were prepared in RF (13.56 MHz) diode/magnetron system using 3-inch diameter stoichiometric targets of the respective materials. Most of the films were deposited on 1-10 ohm-cm, (100) oriented $p$-type silicon-wafer of 2-inch diameter. The $\mathrm{ZnO}$ deposition was also carried out on other substrates such as heavily boron diffused $\left(P^{+}\right)$silicon, oxidized silicon and metal-coated glass substrates. The sputtering for silicon dioxide and silicon nitride was carried out in diode mode at 100-300 W RF power in Ar ambient in the pressure range 5-20 mTorr at a fixed target-to-substrate separation of $45 \mathrm{~mm}$. For $\mathrm{ZnO}$ deposition, a mixture of $\mathrm{Ar}-\mathrm{O}_{2}$ and the magnetron target was used. The target to substrate separation was also varied from $40-60 \mathrm{~mm}$. Although no external substrate heating was provided during the deposition process, the substrate temperature rises due to self-heating in plasma and this was monitored by fixing a thermocouple on the substrate (Singh et al 2007). For $\mathrm{ZnO}$ deposition, the substrate heating due to plasma was exploited to 
obtain highly $c$-axis oriented films, which is a requirement for these films to be piezoelectric in nature. In addition to the dielectric films, thin films of $\mathrm{Cr}, \mathrm{Au}, \mathrm{Ti}$ and $\mathrm{Pt}$ on silicon or glass substrates, (used for $\mathrm{ZnO}$ deposition) were also deposited by $\mathrm{RF}$ sputtering process.

\subsection{Film characterization}

The thickness $(t)$, refractive index $(n)$ and the absorption coefficient $(k)$ of the transparent films were measured by spectroscopic measurement (Filmetrics F20, UV-visible thin film analyzer) while alpha-step (Tencor) was used for thickness measurement of other films. The crystallographic properties were evaluated using XRD analysis $\left(\mathrm{CuK}_{\alpha}\right.$ radiation, $\lambda=1.540^{\prime}$; Brucker-AXS diffrometer, D8 Advance Model). The residual stress is an important parameter, when the films are to be used as structural material in MEMS. This was evaluated for $\mathrm{SiO}_{2}$ and $\mathrm{Si}_{3} \mathrm{~N}_{4}$ films using wafer curvature measurement technique (FSM Frontier Semiconductor). The effect of deposition parameters on the etch rates of $\mathrm{SiO}_{2}$ films in buffered hydrofluoric acid (BHF), potassium hydroxide (KOH) and EPW (ethylenediamine pyrocatechol water) solutions was evaluated. The DC resistivity of the $\mathrm{ZnO}$ film is an important parameter for its application in piezoelectric based devices and the same was measured on a MOS/MIM (metal oxide semiconductor/metal-insulator-metal) capacitor structure using automated I-V measurement set-up. The surface morphology and root-mean-square (rms) surface roughness of the films were characterized using scanning electron microscope (SEM) and atomic force microscope (AFM).

\subsection{Microstructure fabrication}

To illustrate the process for realizing MEMS structures, RF sputtered silicon dioxide microcantilever beams and micro-bridges were fabricated on single-side polished $P$ - or $n$-type (100) silicon wafer by bulk micromachining (BM), surface micromachining (SM) and surface-bulk micromachining (SBM) techniques.

Cantilever beams of $\mathrm{RF}$ sputtered $\mathrm{SiO}_{2}$ were fabricated with varying widths and length using bulk micromachining process. The silicon anisotropic etching was carried out in EPW solution for approximately $1 \mathrm{~h}$. The cantilever beams are released due to undercutting initiated from convex corners. The complete process sequence is given elsewhere (Bhatt \& Chandra 2007a). For $\mathrm{SiO}_{2}$ micro-bridge fabrication, the convex corners are not available to cause undercutting. For this reason, silicon was selectively etched using Reactive Ion Etching (RIE) process following patterning of $\mathrm{SiO}_{2}$ film in BHF. This step exposes many planes in etched silicon surface (by RIE) and a short anisotropic etching step in $\mathrm{KOH}$ causes the structures to be released.

Cantilever beams were also fabricated using surface micromachining technique. For this purpose, RF sputtered silicon dioxide as a structural material and weakly-crystallized $\mathrm{ZnO}$ as sacrificial layer were used. A two-mask process was followed for this purpose (Bhatt \& Chandra 2007a). Zinc oxide film of $4-\mu$ m thickness was deposited from $\mathrm{ZnO}$ target on (100) silicon wafer using the same RF sputtering system. The zinc oxide is then patterned using photolithography process. Special care was taken during photolithography of $\mathrm{ZnO}$ films and it is discussed in detail in our previous work (Bhatt et al 2005). It is a requirement that the etching of $\mathrm{ZnO}$ film during platform formation results in smooth gentle slope. This would lead to conformal step coverage of structural material layer in the subsequent steps. Etching in BHF at room temperature was found to produce a gentle slope $\left(\sim 45^{\circ}\right)$ in the etched platform of $\mathrm{ZnO}$ (Bhatt et al 2005). After this step, the silicon dioxide of two-micron thickness was deposited at $300 \mathrm{~W}$ RF power and 5 mTorr pressure. Due to the 'steps' on the surface of wafer, 


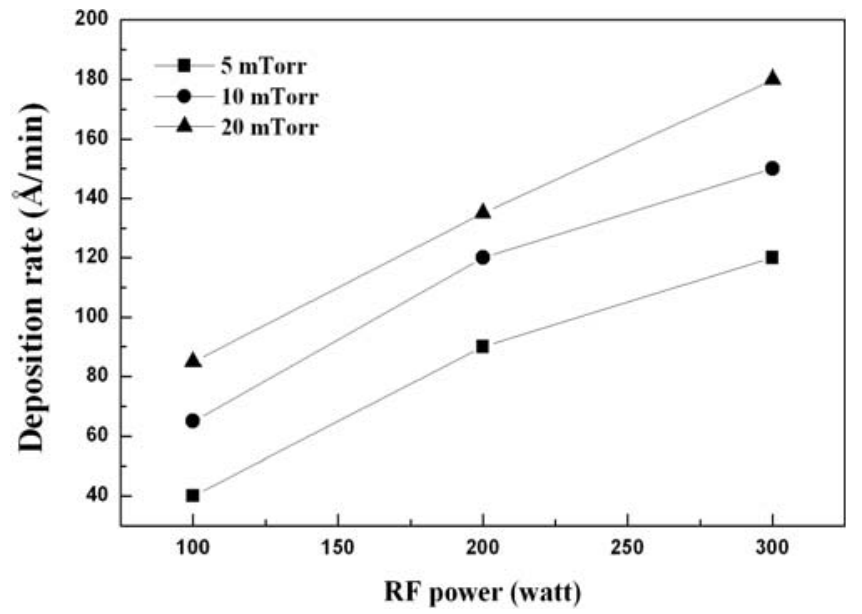

Figure 1. Deposition rate of $\mathrm{SiO}_{2}$ as a function of RF power at different sputtering pressures.

normal photoresist was not suitable for step coverage during pattering. To overcome this problem, a thick photoresist coating (STR-1045, high viscosity) was used. The next masking step is carried out to define the micro-cantilever beam and the silicon dioxide was etched in BHF. Finally, the sacrificial layer is removed in $1 \% \mathrm{HCl}$ and cantilever beam is completely released.

Completely planarized microstructures were also fabricated using a combination of surface and bulk micromaching process (SBM) involving chemical mechanical planarizations (CMP) step. The microstructures such as micro-cantilever beam, diaphragm supported on hinges and micro-bridge were fabricated by SBM technology using two-mask processes (Bhatt \& Chandra 2007c). The sacrificial layer $(\mathrm{ZnO}$ film) is etched in $1 \% \mathrm{HCl}$ for releasing the microstructures.

\section{Results and discussion}

Figure 1 shows the deposition rate of $\mathrm{SiO}_{2}$ films as a function of sputtering power at 5, 10 and 20 mTorr sputtering pressure. The sputtering was done in diode mode. These deposition rates were measured on the centre of the wafer. Near the periphery of the wafer, the deposition rate falls by $10-15 \%$. As expected, the deposition rate strongly depends on the RF power and increases with increasing power.

As mentioned earlier, the substrate temperature is important during deposition process. The wafer surface temperature as a function of deposition time is shown in figure 2 . It is observed that an equilibrium temperature is reached after about 20 minutes from the starting of sputtering. The maximum temperature measured was about $280^{\circ} \mathrm{C} 160^{\circ} \mathrm{C}$ and $75^{\circ} \mathrm{C}$ for 300,200 and $100 \mathrm{~W}$ RF power respectively. Substrate heating during sputtered deposition involves four basic independent heating processes namely: heat of condensation, sputtered atom kinetic energy, plasma radiation and cathode reflected neutrals (Thornton 1978).

Figure 3 shows the residual stress as a function of sputtering pressure. The films were deposited at 5, 10, and 20 mTorr at $300 \mathrm{~W}$ RF power. As seen from the figure, the stress of the films is compressive in the entire pressure range investigated, and increases gradually from approximately 90 to $300 \mathrm{MPa}$ as the pressure is changed from 5 to 20 mTorr. The total stress in the film consists of the contribution from both intrinsic stress and thermal stress. The thermal 


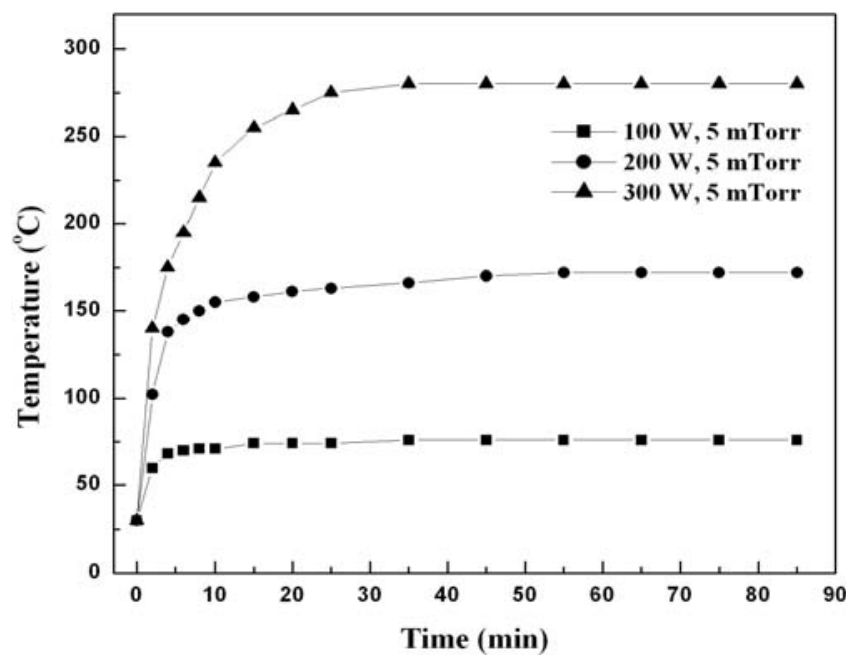

Figure 2. Variation of wafer temperature with sputtering time for different RF power at 5 mTorr pressure.

stress results from the mismatch of the thermal expansion coefficients of the film and the substrate as the sample cools from deposition temperature to room temperature. The maximum temperature rise during sputtering was $280^{\circ} \mathrm{C}$ with the applied power of $300 \mathrm{~W}$, as shown in figure 2. Since all the films were deposited at $300 \mathrm{~W}$ RF power, it is safe to presume that rise in temperature remains constant during the deposition for all the films. Thus, we may assume that the thermal stress value in all the samples will remain identical and only intrinsic stress will change depending on the deposition parameters. Thus, the change in measured stress, as illustrated in figure 3 is largely due to varying intrinsic stress present in the film. The intrinsic stress is, however, different for samples prepared at different sputtering pressure. From the figure, it is clear that the intrinsic stress decreases with decreasing sputtering pressure and

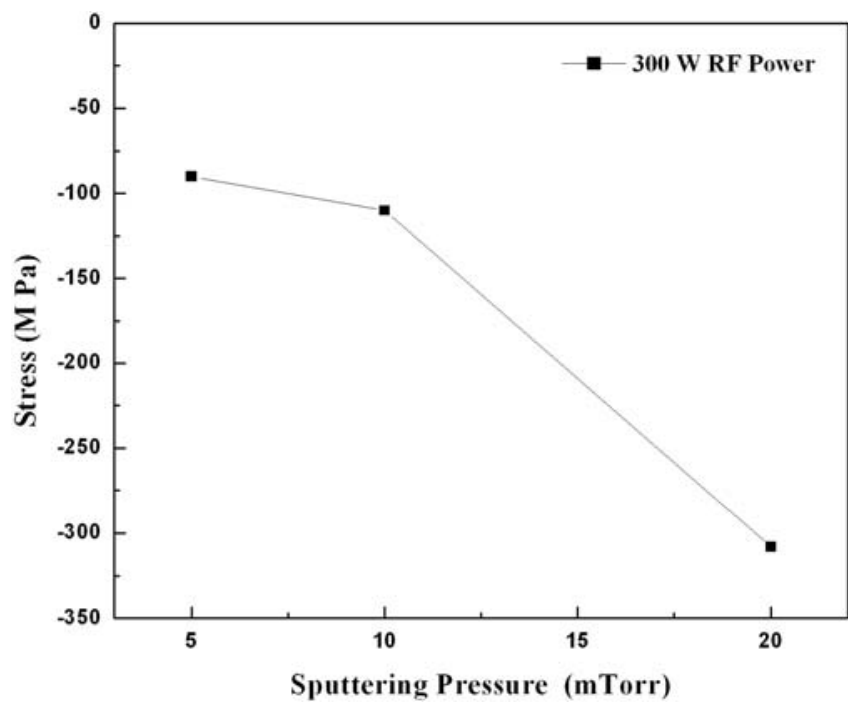

Figure 3. Dependence of residual stress in the $\mathrm{SiO}_{2}$ films on the sputtering pressure. 
this can be explained as follows: at lower deposition rate (at lower pressure, figure 1), the adatoms have sufficient time to migrate to low energy position before they are trapped by subsequently deposited atoms. This apparently results in a lower intrinsic stress. On the other hand, at higher deposition rate (at higher pressure, figure 1), the adatoms are trapped in their arrival position by subsequent incoming atoms. Detail study of stress in RF sputtered $\mathrm{SiO}_{2}$ films are presented in our other work (Bhatt et al 2007b).

Figures $4 \mathrm{a}-\mathrm{c}$ show the effect of sputtering parameters on etching characteristic of RF sputtered $\mathrm{SiO}_{2}$ film in BHF, EPW and $\mathrm{KOH}$ respectively. The results of thermally grown $\mathrm{SiO}_{2}$ are included for the purpose of comparison. The sputtered films produced at a low RF power $(100 \mathrm{~W})$ showed much higher etching rate compared to that of thermal oxide (figure 4a). However, the etch rate for the films sputtered at 300 watt RF power and low

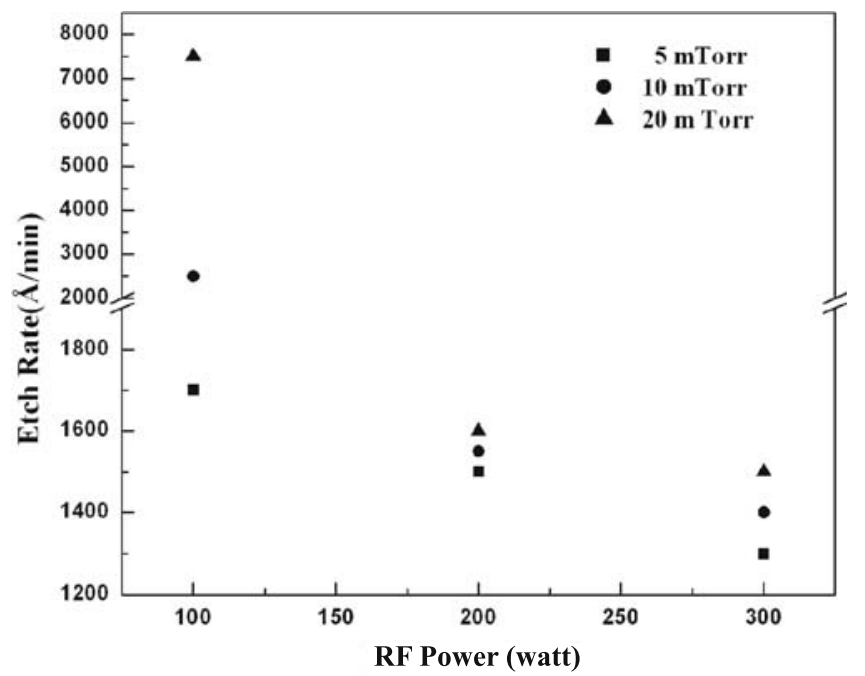

(a)

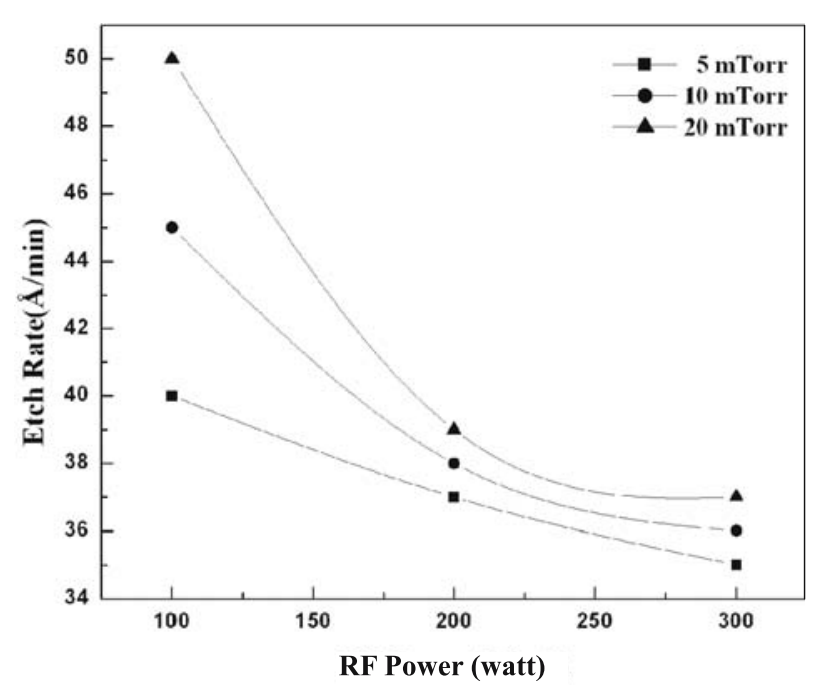

(b)
Figure 4. Effect of sputtering parameters (RF power and pressure) on etch rate of RF sputtered $\mathrm{SiO}_{2}$ films in (a) BHF, (b) $\mathrm{KOH}$ $\left(40 \% \mathrm{w} / \mathrm{w}, \quad 70^{\circ} \mathrm{C}\right)$, (c) EPW. The etch rates of thermally grown $\mathrm{SiO}_{2}$ are: (a) $1100 \AA / \mathrm{min}$, (b) $30 \AA / \mathrm{min}$ and (c) $2 \AA / \mathrm{min}$ for the corresponding solutions (Beadle et al 1985; Seidel et al 1990; Xian-Ping et al 1986). 


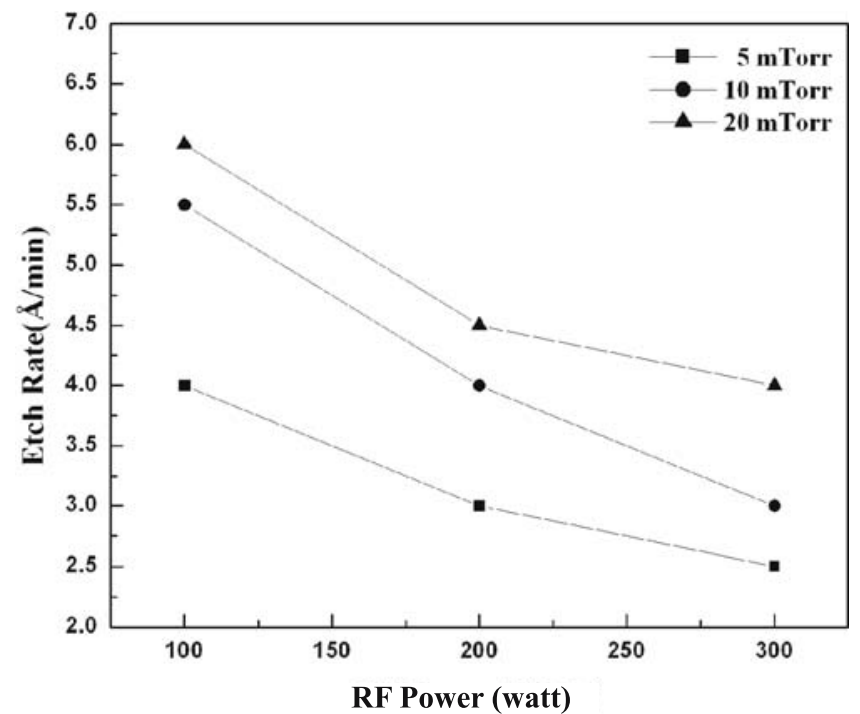

(c)
Figure 4. (Continued).

pressure ( 5 mTorr in the present work) is comparable to that of the thermally grown silicon dioxide films (Beadle et al 1985).

As discussed earlier in $\S 2.3$ (Microstructures fabrication), we aim to explore the RF sputtered silicon dioxide film as a structural layer material for fabricating MEMS structures. For this purpose, it is a requirement that the structural layer (RF sputtered $\mathrm{SiO}_{2}$ ) should not be affected by EPW and $\mathrm{KOH}$, which are used as a silicon anisotropic etchant in bulk micromachining process. The etch rates in $\mathrm{KOH}$ for sputtered $\mathrm{SiO}_{2}$ as a function of RF power at different sputtering pressures are shown in figure $4 \mathrm{~b}$. From the figure, it can be inferred that the etch rate of the film deposited at lower RF power $(100 \mathrm{~W})$ is higher than the corresponding value for thermal oxide. However, the film deposited at higher RF power $(300 \mathrm{~W})$ shows almost same etch rate as that of thermal oxide (Seidel et al 1990).

Figure $4 \mathrm{c}$ shows the etch rate of $\mathrm{RF}$ sputtered $\mathrm{SiO}_{2}$ in $\mathrm{EDP}$ as a function of RF power at different sputtering pressure. It is evident from the figure that the film deposited at higher power and lower pressure ( $300 \mathrm{~W}$ and $5 \mathrm{mTorr}$ ), has a etch rate very similar to that of the thermal oxide (Xian-Ping et al 1986).

Figure 5 shows the scanning electron microscopy (SEM) micrograph of an array of silicon dioxide cantilever beams (100 micron width and varying length) fabricated by bulk micromachining process. The beams are straight which confirms that these are free of any stress gradient.

SEM photograph of RF sputtered silicon dioxide micro-bridge, formed by above mentioned process is shown in figure 6 . The film deposited at $300 \mathrm{~W}$ RF power at $5 \mathrm{mTorr}$ pressure shows compressive stress of $-92 \mathrm{MPa}$ (figure 3 ). The buckling of micro-bridge further confirms the compressive nature of the stress in the $\mathrm{SiO}_{2}$ film.

Figure 7 shows the SEM photograph of RF sputtered $\mathrm{SiO}_{2}$ micro-cantilever beam fabricated by surface micromachining process using $\mathrm{ZnO}$ as sacrificial layer. This figure illustrates that $\mathrm{RF}$ sputtered $\mathrm{ZnO}$ can be used as sacrificial layer with $\mathrm{RF}$ sputtered $\mathrm{SiO}_{2}$ as structural material in conventional surface micromachining process. 


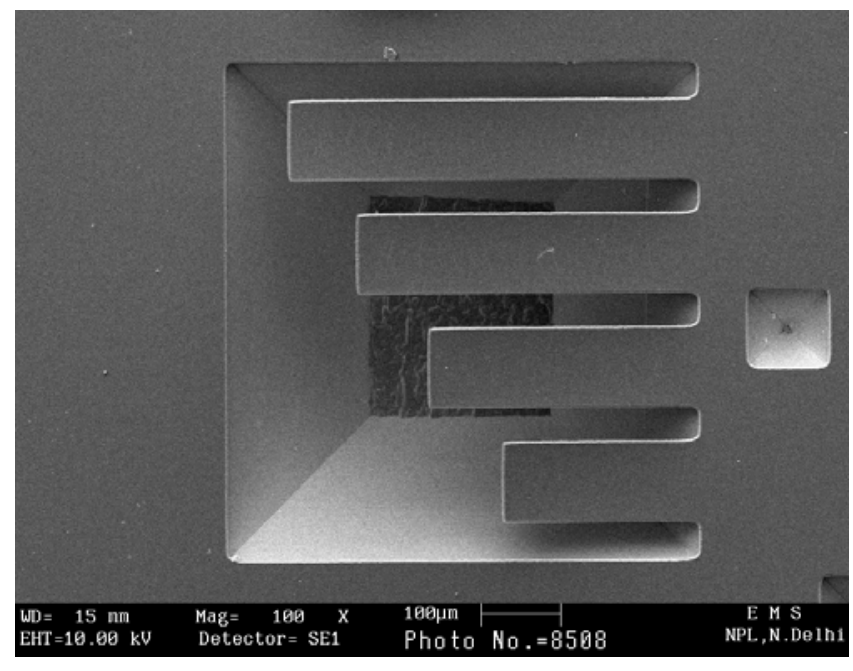

Figure 5. SEM photograph of an array of RF sputtered silicon dioxide micro-cantilever beams formed using bulk micromachining process.

Figures 8a-d show SEM photographs of the completely released planar diagonally supported micro-bridge, micro-cantilever beam, diaphragm supported on hinges and microcantilever beam with wider tip respectively, which are fabricated by the SBM technique.

The deposition rate for the silicon nitride under similar sputtering conditions is illustrated in figure 9. The stress measured as a function of sputtering pressure at $300 \mathrm{~W}$ power is shown in figure 10. The stress was observed to be compressive and decreases from 1360 to $390 \mathrm{MPa}$ as the sputtering pressure is changed from 5 to 20 mTorr. At lower sputtering pressure, the inelastic collision probability between plasma particles decreases, enhancing the peening effects of the energetic plasma particles. Therefore, the intrinsic stress increases with decreasing pressure.

The substrate temperature during the sputter-deposition process is known to have a pronounced effect on its crystallographic properties of $\mathrm{ZnO}$ (Ondo-Ndong et al 2003; Lu et al

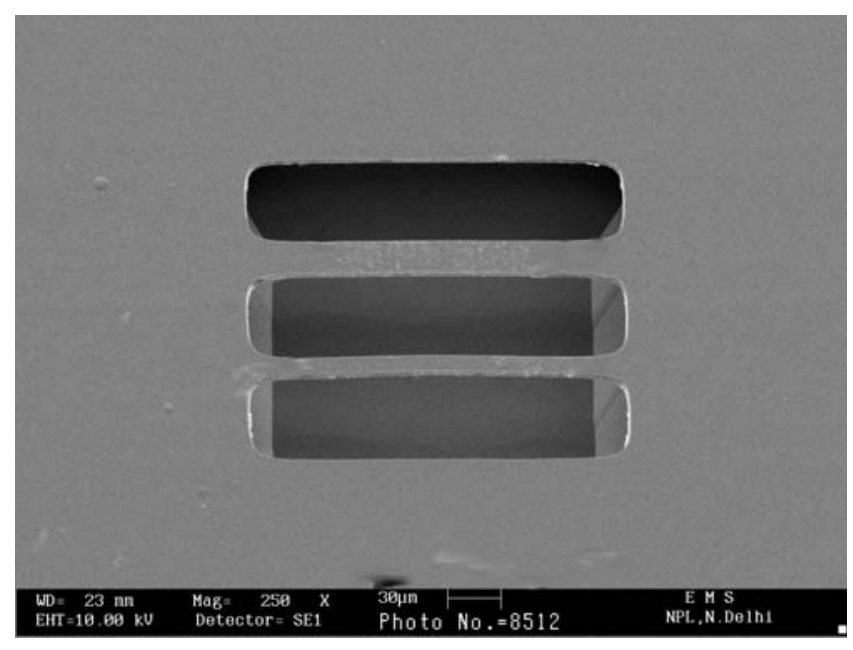

Figure 6. SEM photograph of $\mathrm{RF}$ sputtered $\mathrm{SiO}_{2}$ micro-bridge formed using bulk micromachining process. 


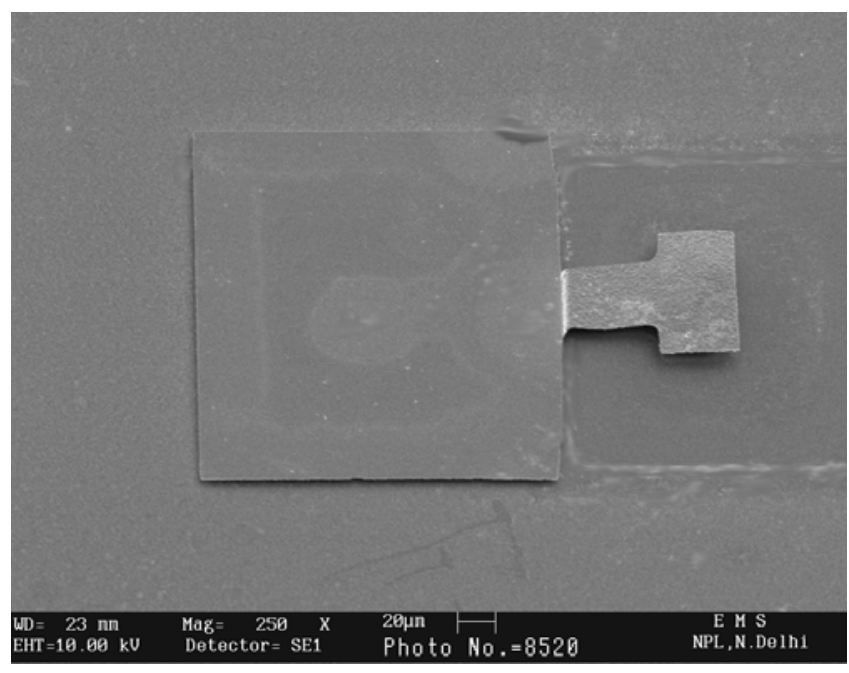

Figure 7. SEM photograph of RF sputtered $\mathrm{SiO}_{2}$ micro-cantilever beam fabricated by surface micromachining process.

2001). It is well known that, during the sputtering process, the substrate temperature rises (Maissel \& Glang 1970). We have investigated whether this self-heating phenomenon can be exploited to obtain $c$-axis oriented $\mathrm{ZnO}$ growth. Figure 11 shows the change in substrate temperature with time during the sputtering (RF power: $100 \mathrm{~W}$, target-substrate distance: 40, 50, and $60 \mathrm{~mm}$, magnetron target) when no external heating was provided. The temperature rises gradually and stabilizes in about $50 \mathrm{~min}$. The maximum substrate temperature is a function
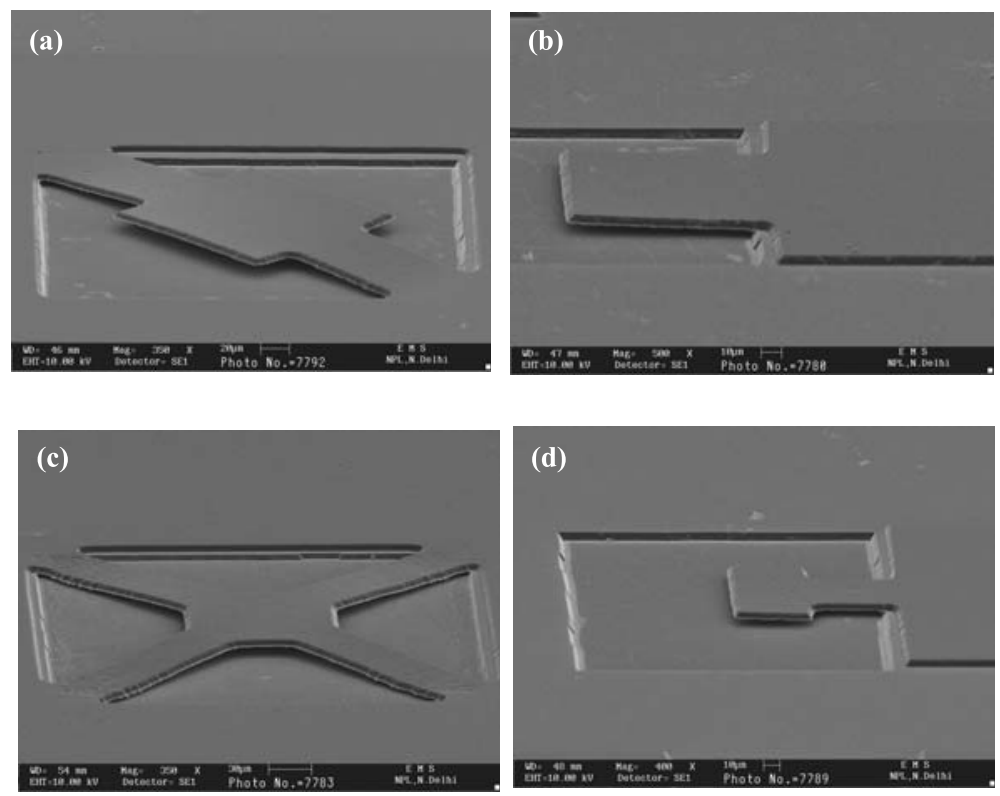

Figure 8. SEM photographs of the completely released planar structures: (a) diagonally supported micro-bridge, (b) micro-cantilever beam, (c) diaphragm supported on hinges and (d) micro-cantilever beam with wider tip. 


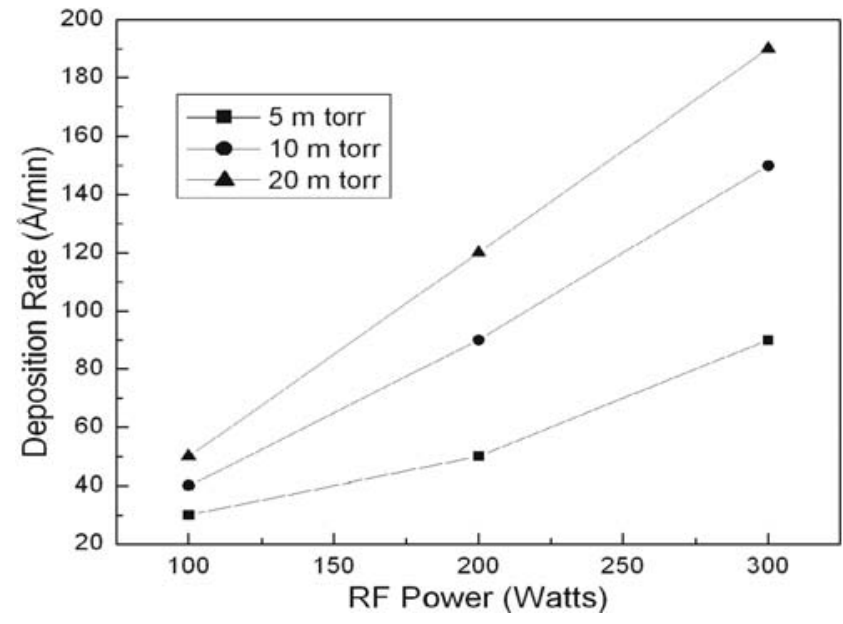

Figure 9. Deposition rate for silicon nitride versus RF power at different sputtering pressures.

of target-to-substrate spacing. For the 40,50 and $60 \mathrm{~mm}$ spacing, its value is 138,110 , and $90^{\circ} \mathrm{C}$ respectively.

Figure 12 shows the XRD pattern of $\mathrm{ZnO}$ films prepared on a variety of substrates such as $\mathrm{Si}(100), p^{+}-\mathrm{Si}$ (heavily boron diffused), $\mathrm{SiO}_{2} / \mathrm{Si}$, glass, $\mathrm{Cu} / \mathrm{Si}, \mathrm{Al} / \mathrm{Si}, \mathrm{Au} / \mathrm{Cr} / \mathrm{SiO}{ }_{2} / \mathrm{Si}$ and $\mathrm{Pt} / \mathrm{Ti} / \mathrm{SiO}_{2} / \mathrm{Si}$. These films were prepared using optimized sputtering parameters $(100 \mathrm{watt}$ RF power, magnetron target, $50 \mathrm{~mm}$ target to substrate spacing, $10 \mathrm{mtorr}$ sputtering pressure, and mixture of argon-oxygen 1:1, no external substrate heating). The deposition rate under these conditions was measured to be about $167 \AA / \mathrm{min}$. It can be seen that the strong (002) peak corresponding to $c$-axis orientation appeared for all the films. The additional peaks were identified to be from the substrate. The intensities of the (002) peaks were not much different for these films. However, the FWHM varied from $0.3^{\circ}$ to $0.72^{\circ}$ and were minimum $\left(\sim 0 \cdot 3^{\circ}\right)$ in the case of glass, $\mathrm{Cu} / \mathrm{Si}$ and $\mathrm{Pt} / \mathrm{Ti} / \mathrm{SiO}_{2} / \mathrm{Si}$ substrates. The $2 \theta$ values of (002) peak of the

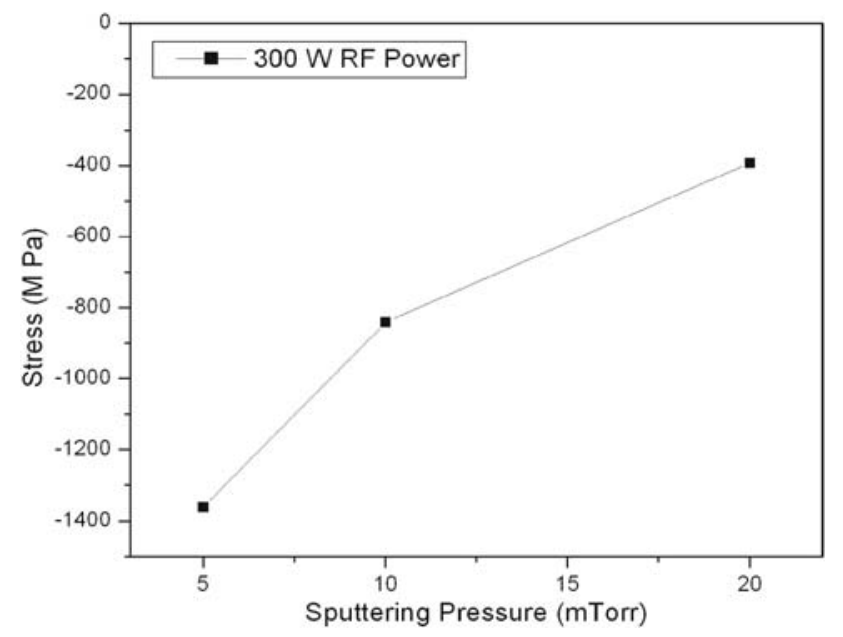

Figure 10. Variation in residual stress in silicon nitride films as a function of sputtering pressure. 


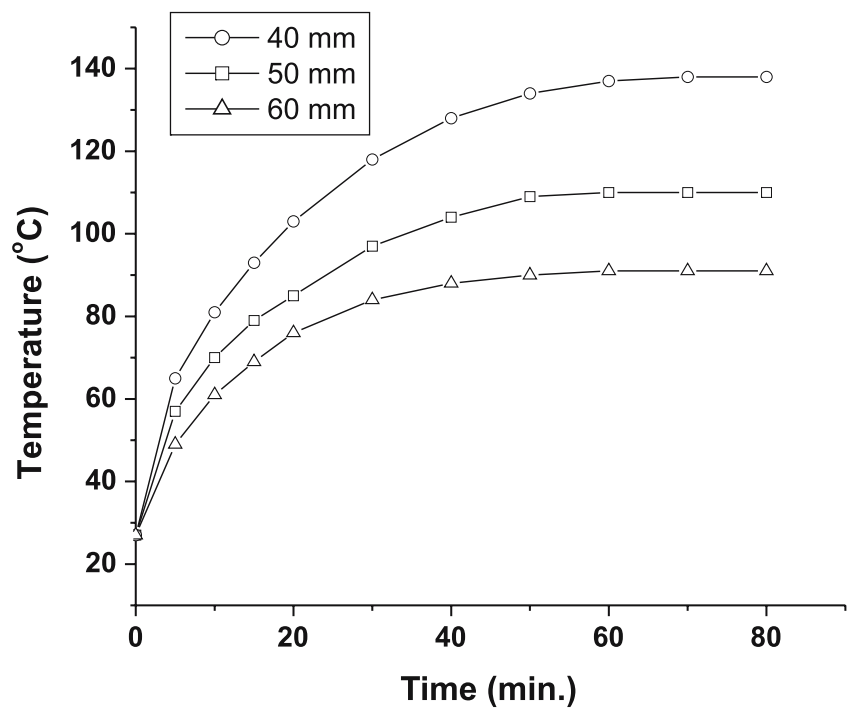

Figure 11. Change in substrate temperature with time during the sputtering at different target-to-substrate spacing (RF power: $100 \mathrm{~W})$. No external heating was provided.

films prepared on $\mathrm{Cu} / \mathrm{Si}$ and $\mathrm{Pt} / \mathrm{Ti} / \mathrm{SiO}_{2} / \mathrm{Si}$ substrates were found to be 34.391 and $34.407^{\circ}$ respectively, which are closer to the value corresponding to the bulk $\mathrm{ZnO}\left(34.44^{\circ}\right)$. This indicates that these films have lower tensile stress than the films prepared on other substrates. However, further experiments are needed to confirm this. The location of (002) peaks and FWHM values for different substrates are summarized in table 1.

The surface morphology was investigated for the as-deposited and annealed $\mathrm{ZnO}$ films which were prepared using optimized sputtering parameters for $c$-axis orientation. Figure 13 shows the SEM images of these films. It appears from the figure that the grains of the asdeposited film are uniformly distributed with nearly similar size. This is further confirmed by AFM measurements, shown in figure 14. The average grain size calculated from these measurements was found to be 147 and $411 \mathrm{~nm}$ for as-deposited and annealed films respectively.

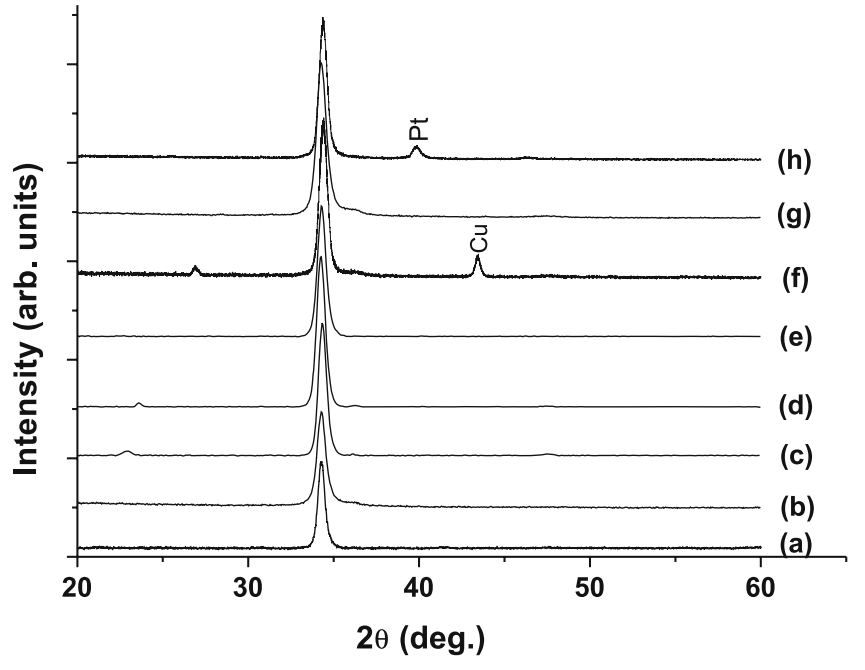

Figure 12. XRD pattern of $\mathrm{ZnO}$ films prepared using optimized sputtering parameters on various substrates: (a) glass, (b) Si (100), (c) $\mathrm{SiO}_{2} / \mathrm{Si}$, (d) $p^{+}-\mathrm{Si}$, (e) $\mathrm{Au} /$ $\mathrm{Cr} / \mathrm{SiO}_{2} / \mathrm{Si}$, (f) $\mathrm{Cu} / \mathrm{Si}$, (g) $\mathrm{Al} / \mathrm{Si}$, and (h) $\mathrm{Pt} / \mathrm{Ti} / \mathrm{SiO}_{2} / \mathrm{Si}$. 
Table 1. The (002) peak positions and FWHM of ZnO films prepared on different substrates using optimized deposition parameters.

\begin{tabular}{|c|c|c|c|c|c|c|c|c|}
\hline Substrate & Si (100) & $\begin{array}{c}p^{+}-\mathrm{Si} \\
\text { (heavily } \\
\text { boron } \\
\text { diffused) }\end{array}$ & $\mathrm{SiO}_{2} / \mathrm{Si}$ & Glass & $\mathrm{Cu} / \mathrm{Si}$ & $\mathrm{Al} / \mathrm{Si}$ & $\begin{array}{l}\mathrm{Au} / \mathrm{Cr} / \\
\mathrm{SiO}_{2} / \mathrm{Si}\end{array}$ & $\begin{array}{c}\mathrm{Pt} / \mathrm{Ti} / \\
\mathrm{SiO}_{2} / \mathrm{Si}\end{array}$ \\
\hline $\begin{array}{l}(002) \\
\text { peak } \\
\text { position, } \\
2 \theta\left(^{\circ}\right)\end{array}$ & $34 \cdot 283$ & $34 \cdot 252$ & $34 \cdot 337$ & 34.275 & 34.391 & $34 \cdot 268$ & $34 \cdot 296$ & 34.407 \\
\hline FWHM $\left(^{\circ}\right)$ & 0.492 & $0 \cdot 612$ & 0.541 & 0.312 & 0.315 & 0.72 & $0 \cdot 66$ & $0 \cdot 306$ \\
\hline
\end{tabular}
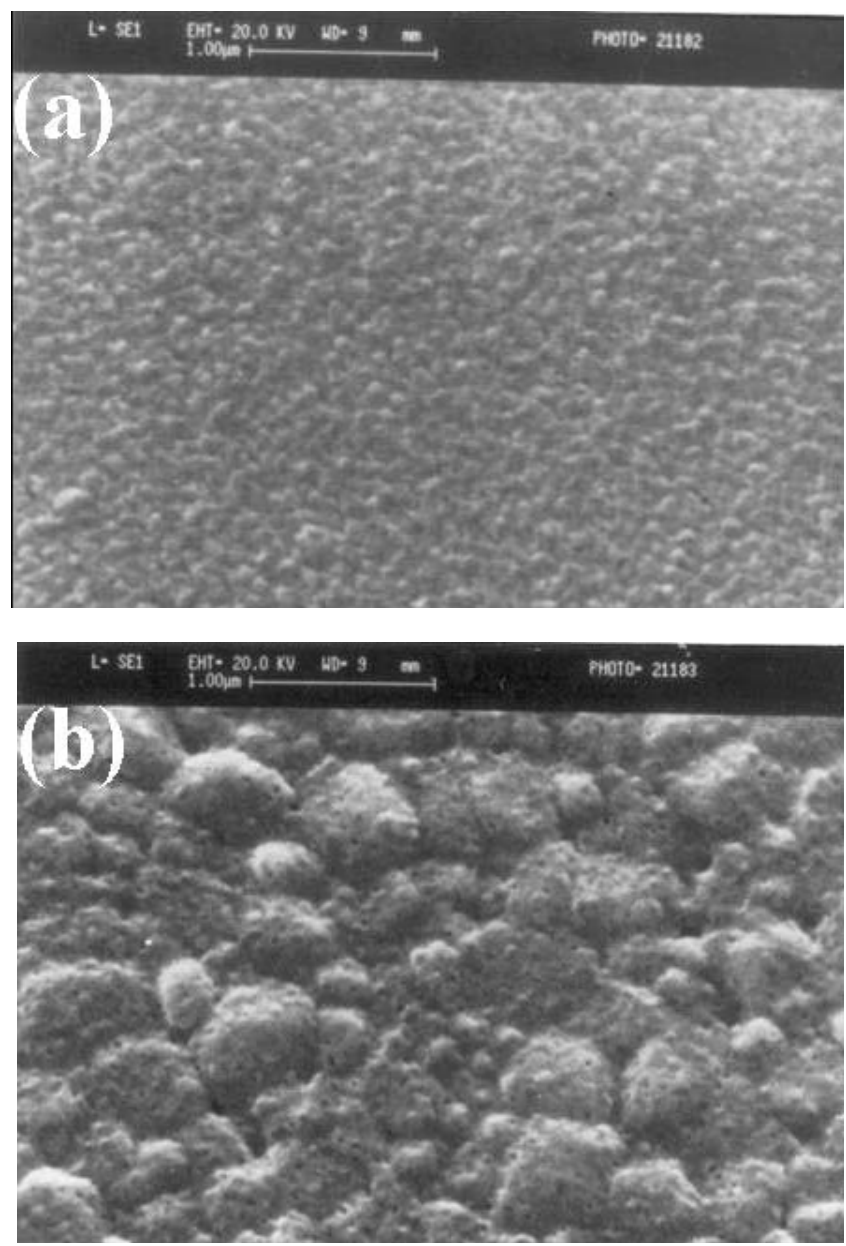

Figure 13. SEM of $\mathrm{ZnO}$ films (a) as deposited and (b) annealed at $900^{\circ} \mathrm{C}$ for $1 \mathrm{hr}$. The $\mathrm{ZnO}$ films were prepared at $100 \mathrm{~W}$ without external substrate heating in $\mathrm{Ar}+$ $\mathrm{O}_{2}$. 

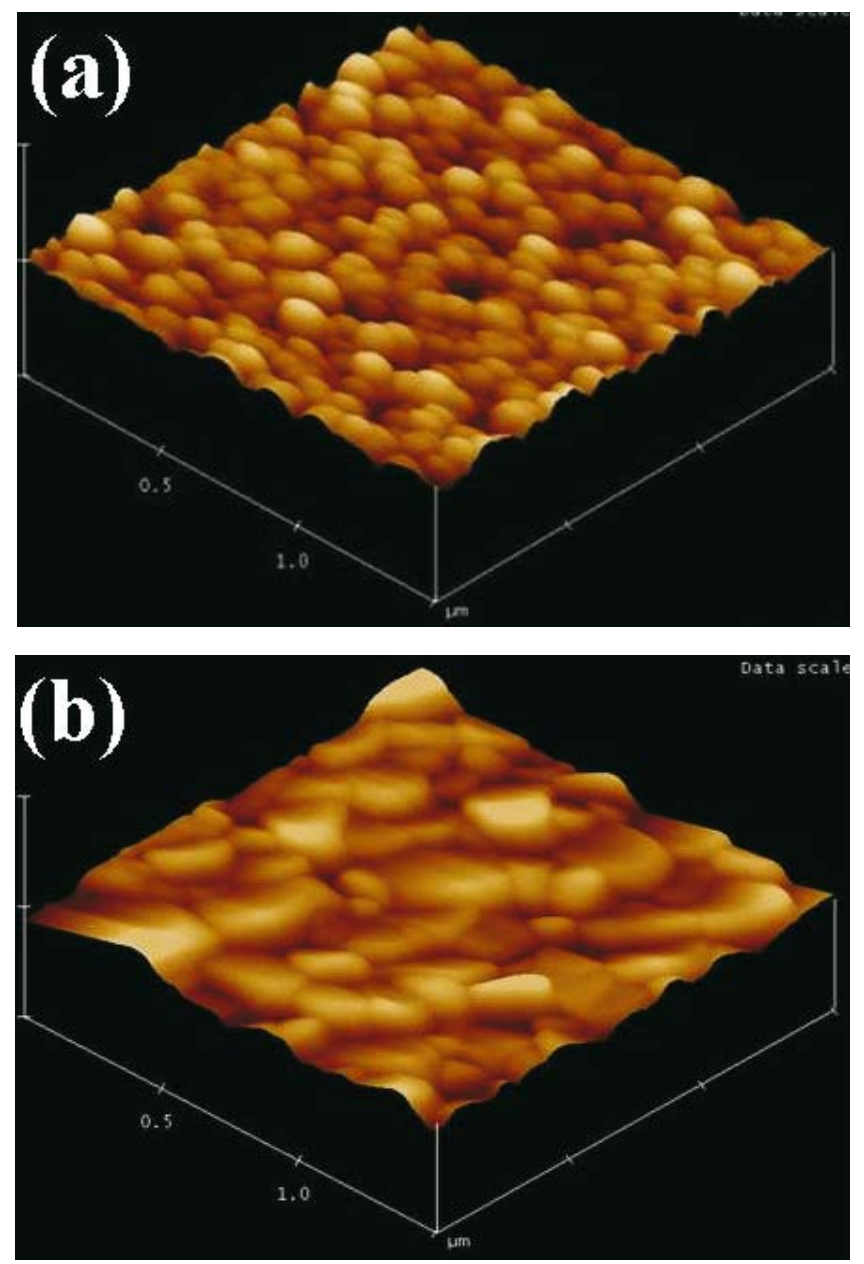

Figure 14. 3-D AFM of $\mathrm{ZnO}$ films (a) as deposited and (b) annealed at $900^{\circ} \mathrm{C}$ for $1 \mathrm{hr}$. The $\mathrm{ZnO}$ films were prepared at $100 \mathrm{~W}$ without external substrate heating in $\mathrm{Ar}+\mathrm{O}_{2}$.

Although the average grain size increased after annealing, the non-uniformity in the grain size also increased. The mean roughness was found to be 9.679 and $4.865 \mathrm{~nm}$ for as-deposited and annealed films respectively. These studies confirm that smooth $\mathrm{ZnO}$ films with uniform grain distribution can be prepared without external substrate heating. The annealing at $900^{\circ} \mathrm{C}$ for $1 \mathrm{hr}$ enhances the grain size and smoothness of the film.

The DC resistivity of the films, calculated from I-V measurements, was found to be in the range of $10^{11}-10^{12} \Omega-\mathrm{cm}$ at low electric fields $(\sim 10 \mathrm{kV} / \mathrm{cm})$. This is much higher than the reported values (Chu et al 2003; Mitsuyu et al 1980).

\section{Conclusions}

The possibility of preparing dielectric films of silicon dioxide and silicon nitride by RF sputtering process for MEMS was explored. The characteristics of the films, which have bearing on MEMS fabrication, were investigated. For the films to be used as structural layer, the etching properties in $\mathrm{KOH}, \mathrm{BHF}$ and $\mathrm{EPW}$ were investigated. The stress in the film was evaluated 
as a function of deposition parameters to obtain low-stress films. The microstructures were realized using bulk micromachining, surface micromachining and surface- bulk micromachining techniques. Highly $c$-axis oriented $\mathrm{ZnO}$ films having high dc resistivity were prepared without external substrate heating on a variety of substrates. This has potential applications in MEMS. It is concluded that the RF sputtering process is a viable method of preparing films at relatively low temperatures for fast prototyping of MEMS.

\section{References}

Beadle W E, Tsai J C C, Plummer R D 1985 Quick reference manual for silicon integrated circuit technology. (John Weiley \& Sons Inc.) 5-8

Bhatt V, Pal P, Chandra S 2005 Feasibility study of RF sputtered ZnO film for surface micromachining. Surface and Coatings Technology 198: 304-308

Bhatt V, Chandra S 2007a Silicon dioxide films by RF sputtering for microelectronic and MEMS applications. J. Micromech. Microeng. 17: 1066-77

Bhatt V, Chandra S, Kumar S, Rauthan C M S, Dixit PN 2007b Stress evaluation of RF sputtered silicon dioxide films for MEMS. Indian J. Pure and Appl. Phy. 45: 377-381

Bhatt V, Chandra S 2007c Planar microstructures using modified surface micromachining process. Sensor Lett. 5: 387-391

Chu S Y, Water W, Liaw J T 2003 Influence of post deposition annealing on the properties of ZnO film prepared by RF magnetron sputtering. Euro. Ceram. Soc. 23: 1593-98

Folta J A, Hunt C E, Farrens S N 1994 Low-temperature wafer bonding of surfaces using a reactive sputtered oxide. J. Electrochem. Soc. 141: 2157-2160

Hurley R E and Gamble H S 2003 Thin film sputtered silicon for silicon wafer bonding applications. Vacuum 70: 131-140

Lu Y M, Hwang W S, Liu W Y, Yang J S 2001 Effect of RF power on optical and electrical properties of $\mathrm{ZnO}$ thin film by magnetron sputtering. Mater. Chem. Phys. 72: 269-272

Maissel L I, Glang R 1970 Handbook of Thin Film Technology, (New York: McGraw-Hill Book Company)

Mitsuyu T, Ono S, Wasa K 1980 Structures and saw properties of RF-sputtered single-crystal films of ZnO on sapphire. J. Appl. Phys. 51: 2464-2470

Ondo-Ndong R, Pascal-Delannoy F, Boyer A, Giani A, Foucaran A 2003 Structural properties of zinc oxide thin films prepared by RF magnetron sputtering. Mater. Sci. Eng. B97: 68-73

Seidel H, Csepregi L, Heuberger A, Baumgartel H 1990 Anisotropic etching of crystalline silicon in alkaline solution. J. Electrochem. Soc. 137: 3612-3626

Singh R, Kumar M, Chandra S 2007 Growth and characterization of high resistivity c-axis oriented $\mathrm{ZnO}$ films on different substrates by RF magnetron sputtering for MEMS applications J. Mat. Sci. 42: 4675-4683

Thornton J A 1978 Substrate heating in cylindrical magnetron sputtering sources. Thin Solid Films 54: $23-31$

Xian-Ping W U, Quing-Hai W U, Wen H K 1986 A study on deep etching of silicon using ethylenediamine-pyrocatechol-water. Sensors and Actuators 9: 333-343 